\title{
GEOMETRIC EVALUATION OF COMPLEX CAVITY INTRUDED IN HEAT GENERATED WALLS
}

\author{
M. V. F. Guimaraes ${ }^{\mathrm{a}}$, \\ L. R. Emmendorfer ${ }^{b}$, \\ J. F. Prolo Filho ${ }^{\mathrm{a}, \mathrm{c}}$, \\ and E. D. dos Santos ${ }^{\text {b,c }}$ \\ ${ }^{\text {a }}$ Universidade Federal do Rio Grande \\ Instituto de Matemática, Estatística e Física, \\ Rio Grande, Rio Grande do Sul, Brasil \\ guimaraesmvf@gmail.com \\ ${ }^{\mathrm{b}}$ Universidade Federal do Rio Grande \\ Progr. de Grad. em Modelagem Computacional, \\ Rio Grande, Rio Grande do Sul, Brasil. \\ ${ }^{\mathrm{c}}$ Universidade Federal do Rio Grande \\ Progr. de Pós-Grad. em Engenharia Oceânica, \\ Rio Grande, Rio Grande do Sul, Brasil \\ ABSTRACT \\ In this work it is presented a numerical study about geometrical evaluation \\ of heat transfer in solids with volumetric heat generation and complex \\ intruded cavity for cooling the wall by means of Constructal Design. \\ Several cavities with varied shapes have been evaluated in literature, such \\ as I-, T- and H-shaped cavities. The purpose here is to evaluate a complex \\ cavity that combines different elemental shapes. More precisely, the \\ resultant cavity is a merge between a H-shaped cavity and a I-shaped one, \\ forming a ramified geometry, which is more expected in the flow between a \\ point and volume in systems with high magnitude. The main purpose is to \\ minimize two times the maximal temperature in the solid domain $\left(\mathrm{T}_{\max }\right)$. \\ Here two degrees of freedom are defined for the cavity: $\mathrm{H}_{1} / \mathrm{L}_{1}$ (ratio \\ between the second branch thickness and its length) and $\mathrm{H}_{0} / \mathrm{L}_{0}$ (ratio \\ between the third branch height and its thickness) and the area of cavity is \\ the constraint. For each geometrical configuration the heat diffusion \\ equation is solved with the Finite Element Method (FEM). Results showed \\ that differences of until five times between the optimal shapes and the worst \\ ones are achieved, showing the importance of application of Constructal \\ Design in the problem. Moreover, the best performance is achieved when \\ the vertical branches are fully intruded in the solid domain for intermediate \\ lengths of horizontal branch. \\ Received: May 25, 2017 \\ Revised: June 19, 2017 \\ Accepted: July 17, 2017 \\ Keywords: constructal design, geometric evaluation, complex cavity, heat \\ transfer

\section{NOMENCLATURE} \\ $\mathrm{H}_{0}$ height of vertical lateral cavities, $\mathrm{m}$ \\ $\mathrm{H}_{1}$ thickness of horizontal branch, $\mathrm{m}$ \\ $\mathrm{H}_{2}$ height of elemental branch, $\mathrm{m}$ \\ $\mathrm{L}_{0} \quad$ thickness of vertical lateral cavities, $\mathrm{m}$ \\ $\mathrm{L}_{1} \quad$ length of horizontal branch, $\mathrm{m}$ \\ $\mathrm{L}_{2}$ thickness of elemental branch, $\mathrm{m}$ \\ $\mathrm{T}_{\max }$ Temperature field \\ $\mathrm{T}_{\min }$ Initial temperature \\ $\mathrm{T}$ Temperature $\left({ }^{\circ} \mathrm{C}\right.$ or $\left.\mathrm{K}\right)$ \\ $\mathrm{x}, \mathrm{y}$ Cartesian coordinates (m), \\ q"' volumetric rate heat generation $\left(\mathrm{W} / / \mathrm{m}^{3}\right)$

\section{Subscripts \\ m minimum} \\ o optimum

\section{INTRODUCTION} \\ The employment of cavities for cooling solids \\ with internal heat generation have represented a wide \\ topic of study in the literature. However, depending \\ on the adopted cavity geometry, the evaluation of \\ geometry effects over temperature fields could \\ represent a non-trivial task. Several cavity shapes has \\ been evaluated in literature: I-shaped, T-shaped, Y- \\ shaped, H-shaped (Biserni et al., 2004; Xie et al., \\ 2010; Lorenzini et al., 2013; Lorenzini et al., 2014; \\ Gonzales et al., 2015; Biserni et al., 2007). A merge \\ of elemental cavities has also been evaluated in \\ literature, e.g., T-Y-shaped cavities, T-Y-shaped \\ cavities with lateral intrusions (Lorenzini and Rocha, \\ 2009, Lorenzini et al., 2012). Results for combined \\ cavity shapes has demonstrated that this kind of \\ evaluation can be a good strategy for improvement of \\ thermal performance of this kind of flow system. \\ For all above mentioned studies, Constructal \\ Design was employed for geometric evaluation of \\ cavity shapes. Constructal Design is a method of \\ constraints and objectives and is based on a physical \\ principle. This principle is named Constructal Law of \\ design and evolution. This physical law states that a \\ finite flow system (animate or inanimated) with \\ freedom to morph along the time will evolve in such \\ way to improve the access to the internal currents that \\ flow through it (Bejan, 2000; Bejan and Lorente, \\ 2008; Bejan and Zane, 2012; Bejan, 2016). In the \\ engineering field, the method has been used in \\ several other problems beyond the design of cavities \\ as, solid mechanics (flow of stresses), refrigeration, \\ convective flows and renewable energy (Helbig et al., \\ 2016; Rodrigues et al., 2015; Dos Santos et al., 2014; \\ Vieira et al., 2017). \\ In the present work, it is evaluated the geometry \\ of a complex shaped cavities intruded into square \\ conducting solid wall with internal heat generation.
}


The complex cavity shape combined two different shapes: H-shaped cavity and I-shaped one. In the present problem, the system is submitted to one constraint (the area of the cavity) and two degrees of freedom are evaluated: $\mathrm{H}_{0} / \mathrm{L}_{0}$ (ratio between the third branch height and its thickness) and $\mathrm{H}_{1} / \mathrm{L}_{1}$ (ratio between the second branch thickness and its length) and the purpose is to reach to a geometry which minimizes the maximal temperature $\left(\mathrm{T}_{\max }\right)$ inside the solid domain. Other geometric variables are kept constant in the present study: $\mathrm{L}_{2}=0.2 \mathrm{~m}$ (thickness of main branch), $\mathrm{H}_{\mathrm{A}}=0.45 \mathrm{~m}$ (lower half height of main branch) and $\mathrm{H}_{2}=0.9 \mathrm{~m}$ (total height of the main branch). For each evaluated geometry, the heat diffusion equation is solved with the Finite Element Method (FEM), more precisely using the Partial Differential Equation Toolbox (PDETOOL) of software MATLAB (MATLAB, 2000).

\section{MATHEMATICAL AND NUMERICAL MODEL}

The heat transfer in the solid domain with internal heat generation at the steady state in a two dimensional domain is modeled with the heat diffusion equation, given by:

$$
k \frac{\partial^{2} T}{\partial x^{2}}+k \frac{\partial^{2} T}{\partial y^{2}}+q^{\prime \prime \prime}=0
$$

where $\mathrm{k}$ is the thermal conductivity $(\mathrm{W} / \mathrm{mK}), \mathrm{T}$ is the temperature field $\left({ }^{\circ} \mathrm{C}\right.$ or $\left.\mathrm{K}\right), \mathrm{x}$ and $\mathrm{y}$ are Cartesian coordinates (m), q"' is the heat generated in the solid domain per unit volume $\left(\mathrm{W} / \mathrm{m}^{3}\right)$. For the geometric evaluation it is required the solution of Eq. (1) for each different studied configuration.

The evaluated problem domain is illustrated in Fig. 1. The heat is generated in the internal solid domain and the cavity acts as a heat sink. Concerning the boundary conditions, the external solid surfaces are adiabatic, which means, is imposed a null heat flux. While in the cavity surfaces, it is imposed a prescribed lowest temperature $\left(\mathrm{T}_{\min }=0^{\circ} \mathrm{C}\right)$.

For the acquisition of numerical solution of Eq. (1), it was used a discretization method named Finite Element Method (FEM). The PDETOOL implemented in MATLAB software uses this numerical method to solve differential equations. Figure 1 also show the geometry variables that defines the cavity and the solid domain.

Before to perform the geometrical evaluation it is necessary to evaluate the mesh quality employed in the present simulations. In this sense, it is performed a grid independence test. The mesh employed in PDETOOL is unstructured and composed of triangular finite elements. For each grid refinement the number of elements is increased four times. Here, the way of verification if the mesh refinement is acceptable is comparing the highest temperature inside the solid domain adopting a stop criterion that considers the approximation of the temperature from the previous acquired value. In this paper it was adopted a stopping criteria of $5.0 \times 10^{-4}$. Hence, comparing the temperature of the current mesh with the posterior. Once the stopping criteria is obtained, the temperature field will show a low variation with the mesh refinement, and for practical reasons, must be considered that the solution will not affect the result significantly. With this procedure, the present solution is independent of the mesh, which means, does not depend anymore on the mesh refinement. The Table 1 shows the mesh independence test for the proposed complex cavity solid with the following geometric configurations: $\mathrm{H}_{\mathrm{A}}=0.45 \mathrm{~m}, \mathrm{H}_{2}=0.9 \mathrm{~m}$, $\mathrm{L}_{2}=0.2 \mathrm{~m}, \mathrm{~L}_{1}=0.5 \mathrm{~m}, \mathrm{H}_{1}=0.1 \mathrm{~m}, \mathrm{H}_{0}=0.4 \mathrm{~m}$ and $\mathrm{L}_{0}=0.1 \mathrm{~m}$.

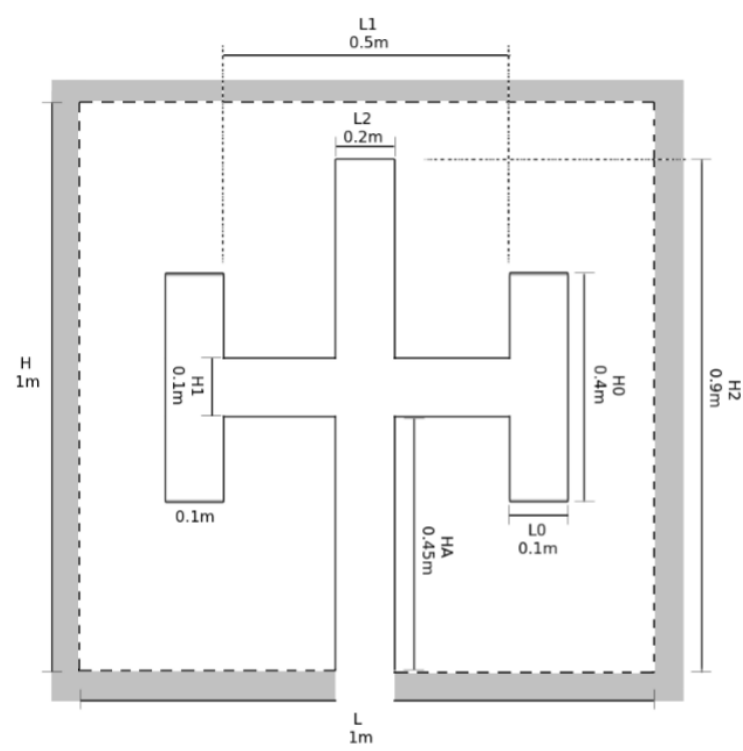

Figure 1. Evaluation domain and complex cavity.

Table 1. Independence mesh test.

\begin{tabular}{c|c|c}
\hline Elements & $\mathrm{T}_{\max }\left({ }^{\circ} \mathrm{C}\right)$ & $\begin{array}{c}\text { Stopping criteria: } \\
5.0 \times 10^{-4}\end{array}$ \\
\hline 181 & 0.0360149 & $2.9143 \times 10^{-2}$ \\
\hline 632 & 0.0370960 & $1.1895 \times 10^{-2}$ \\
\hline 2347 & 0.0375426 & $4.8627 \times 10^{-3}$ \\
\hline 9029 & 0.0377260 & $1.9845 \times 10^{-3}$ \\
\hline 35401 & 0.0378010 & $8.0664 \times 10^{-4}$ \\
\hline 140177 & 0.0378316 & $4.5775 \times 10^{-4}$ \\
\hline 557857 & 0.0378489 & ------------- \\
\hline
\end{tabular}

The next step is to define the problem restriction and degrees of freedom according to constructal design method.

The degrees of freedom on the proposed geometry tends to evaluate how different geometric configurations could contribute on the acquisition of the temperature field $\left(\mathrm{T}_{\max }\right)$. The main objective to investigate these configurations is to found geometry(ies) which minimize $\mathrm{T}_{\max }$. For the proper 
implementation, it is necessary to respect the total cavity area, since the height and width ratio does not violate the initial area proposed on the problem domain. This paper defined two degrees of freedom, identified by the ratios $\mathrm{H}_{0} / \mathrm{L}_{0}$ and $\mathrm{H}_{1} / \mathrm{L}_{1}$. Figure 2 illustrates the degrees of freedom location on the geometry domain.

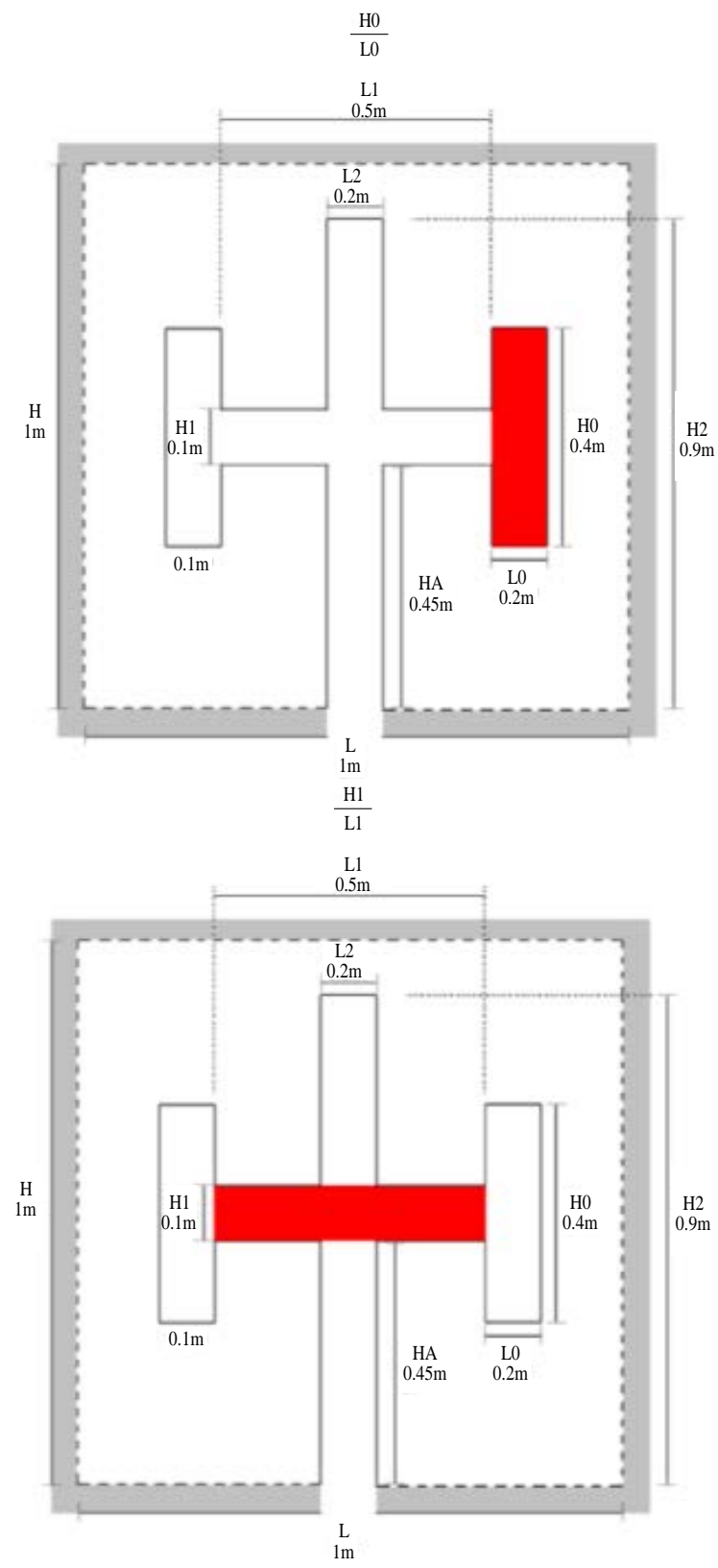

Figure 2. Illustration of the degrees of freedom evaluated in the present problem.

As previously stated, the problem is submitted to two restrictions, the area of solid domain and the cavity area, which are given by:

$$
\begin{gathered}
\mathrm{A}=\mathrm{HL} \\
{ }_{\substack{\mathrm{H} 1 \\
\text { 1m }}}^{\mathrm{A}_{\mathrm{c}}=\mathrm{H}_{2} \mathrm{~L}_{2}+\mathrm{H}_{1} \mathrm{~L}_{1}+2 \mathrm{H}_{0} \mathrm{~L}_{0}}
\end{gathered}
$$

where the ratios that defines the degrees of freedom are given by $\mathrm{H}_{0} / \mathrm{L}_{0}$ and $\mathrm{H}_{1} / \mathrm{L}_{1}$. In the present problem, it is considered that the variables $\mathrm{H}_{2}$ and $\mathrm{L}_{2}$ are fixed. In this sense, the geometrical evaluation of the problem is shared in two steps. In the first step, the ratio $\mathrm{H}_{0} / \mathrm{L}_{0}$ is varied while the ratio $\mathrm{H}_{1} / \mathrm{L}_{1}$ is kept fixed. The lowest maximal temperature found is the once minimized maximal temperature, $\left(\mathrm{T}_{\max }\right)_{\mathrm{m}}$, and the corresponding geometry is the once optimized ratio $\left(\mathrm{H}_{0} / \mathrm{L}_{0}\right)_{0}$. In the second step, other magnitude of the ratio $\mathrm{H}_{1} / \mathrm{L}_{1}$ is simulated and the effect of the ratio $\mathrm{H}_{0} / \mathrm{L}_{0}$ over $\mathrm{T}_{\max }$ is re-evaluated. This process is repeated for several ratios of $\mathrm{H}_{1} / \mathrm{L}_{1}$. The lowest magnitude of maximal temperature is the twice minimized maximal temperature, $\left(\mathrm{T}_{\max }\right)_{\mathrm{mm}}$, and the optimal ratios are $\left(\mathrm{H}_{1} / \mathrm{L}_{1}\right)_{\mathrm{o}}$ and $\left(\mathrm{H}_{0} / \mathrm{L}_{0}\right)_{\mathrm{oo}}$. Figure 3 illustrates a flowchart of the geometrical optimization performed here. It is worthy to mention that the exhaustive search is employed for optimization of the problem.

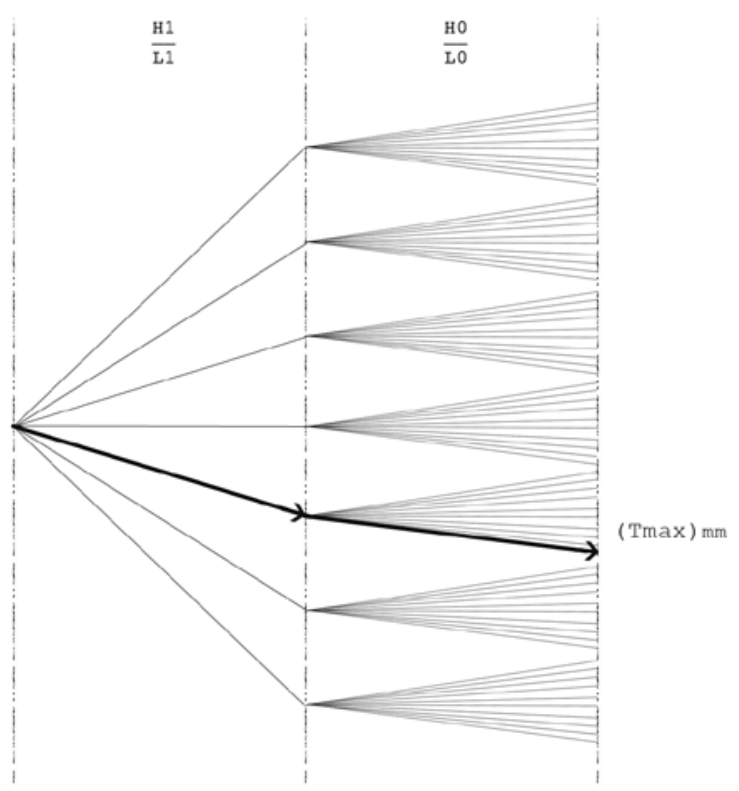

Figure 3. Flowchart of the optimization process employed in the present problem.

\section{RESULTS AND DISCUSSION}

The first analysis consists on the evaluation of the effect of the ratio $\mathrm{H}_{0} / \mathrm{L}_{0}$ over the maximal temperature obtained in the solid domain $\left(\mathrm{T}_{\max }\right)$. Figures 4 and 5 show this effect for several ratios of $\mathrm{H}_{1} / \mathrm{L}_{1}$. Figure 5 detailed the effects of ratio $\mathrm{H}_{0} / \mathrm{L}_{0}$ over $\mathrm{T}_{\max }$ for the best ratios of $\mathrm{H}_{1} / \mathrm{L}_{1}$. As can be noticed, for most ratios $\mathrm{H}_{1} / \mathrm{L}_{1}$ the best performance is achieved for the highest possible ratio of $\mathrm{H}_{0} / \mathrm{L}_{0}$, i.e., $\left(\mathrm{H}_{0} / \mathrm{L}_{0}\right)_{0}=0.95$, with exception for the lowest ratios of $\mathrm{H}_{1} / \mathrm{L}_{1} \leq 0.30$, where intermediate optimal ratios of $\left(\mathrm{H}_{0} / \mathrm{L}_{0}\right)_{0}$ are found. Results also shown that the best shape reaches to thermal performances several times higher than that reached for the worst shapes. For instance, for $\mathrm{H}_{1} / \mathrm{L}_{1}=0.6$ the optimal shape, $\left(\mathrm{H}_{0} / \mathrm{L}_{0}\right)_{\mathrm{o}}$ 
$=0.96$ is 5 times superior than the worst shape, $\mathrm{H}_{0} / \mathrm{L}_{0}$ $=0.25$.

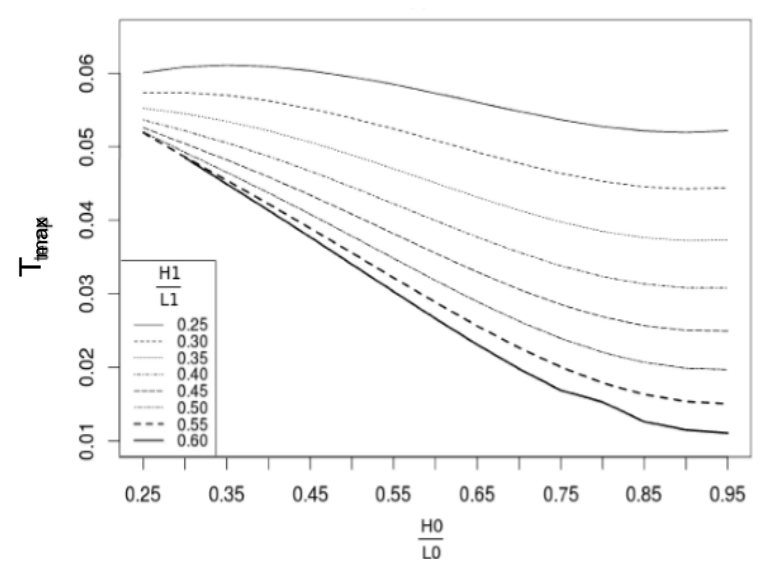

Figure 4. Effect of the ratio $\mathrm{H}_{0} / \mathrm{L}_{0}$ over $\mathrm{T}_{\max }$ for $\mathrm{H}_{1} / \mathrm{L}_{1} \leq 0.60$.

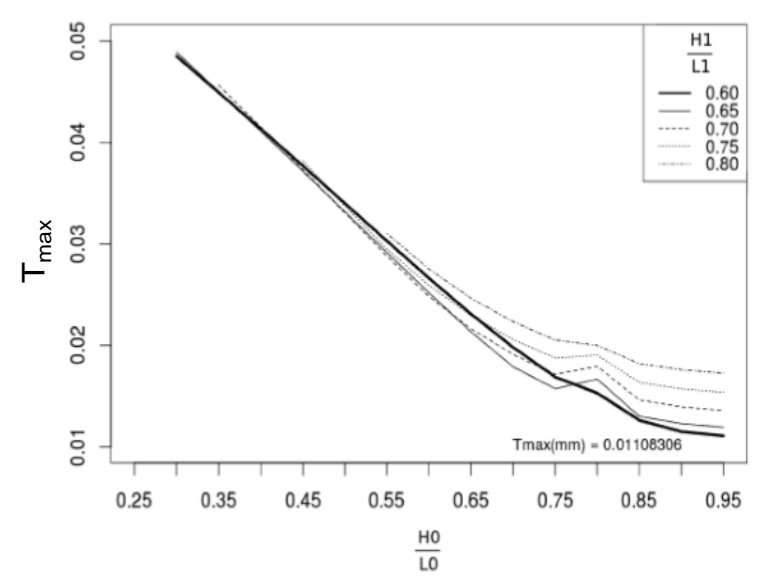

Figure 5. Effect of the ratio $\mathrm{H}_{0} / \mathrm{L}_{0}$ over $\mathrm{T}_{\max }$ for

$$
\mathrm{H}_{1} / \mathrm{L}_{1} \geq 0.60 \text {. }
$$

In Figures 4 and 5 it can also be noticed that there is an intermediate ratio of $\mathrm{H}_{1} / \mathrm{L}_{1}$ which leads to the best thermal performance, i.e., when $\left(\mathrm{H}_{1} / \mathrm{L}_{1}\right)_{0}=$ 0.6. Results in general show that the best performance is achieved when the vertical branches has the highest possible intrusion and the horizontal branch has an intermediate insertion in the solid domain.

In order to illustrate the effect of the ratio $\mathrm{H}_{0} / \mathrm{L}_{0}$ over the thermal field into the solid domain, Fig. 6 illustrates the temperature fields for some configurations with different ratios of $\mathrm{H}_{0} / \mathrm{L}_{0}$. It is possible to notice that for the lowest ratios of $\mathrm{H}_{0} / \mathrm{L}_{0}$, i.e., for the lowest intrusion of lateral branches, four points of hot spots are achieved. As the ratio $\mathrm{H}_{0} / \mathrm{L}_{0}$ increases the four hot spots are distributed in two lines of higher temperature. Results showed that the best performance is achieved when the hot spots are better distributed along the solid domain, i.e., according to constructal principle of optimal distribution of imperfections.

In the same viewpoint of analysis, Fig. 7 shows the influence of the ratio $\mathrm{H}_{1} / \mathrm{L}_{1}$ over the thermal field distribution in the solid domain for a fixed ratio of $\mathrm{H}_{0} / \mathrm{L}_{0}$. Figure 7 shows that for the lowest ratios of $\mathrm{H}_{1} / \mathrm{L}_{1}$ two hot regions of temperature are observed. As the ratio $\mathrm{H}_{1} / \mathrm{L}_{1}$ increases the two regions changed for four regions of hot temperature, in dissimilar way to that obtained for the effect of $\mathrm{H}_{0} / \mathrm{L}_{0}$ over the thermal field, where it was observed four points of high temperature in the corners of solid domain (further way from the cavity).

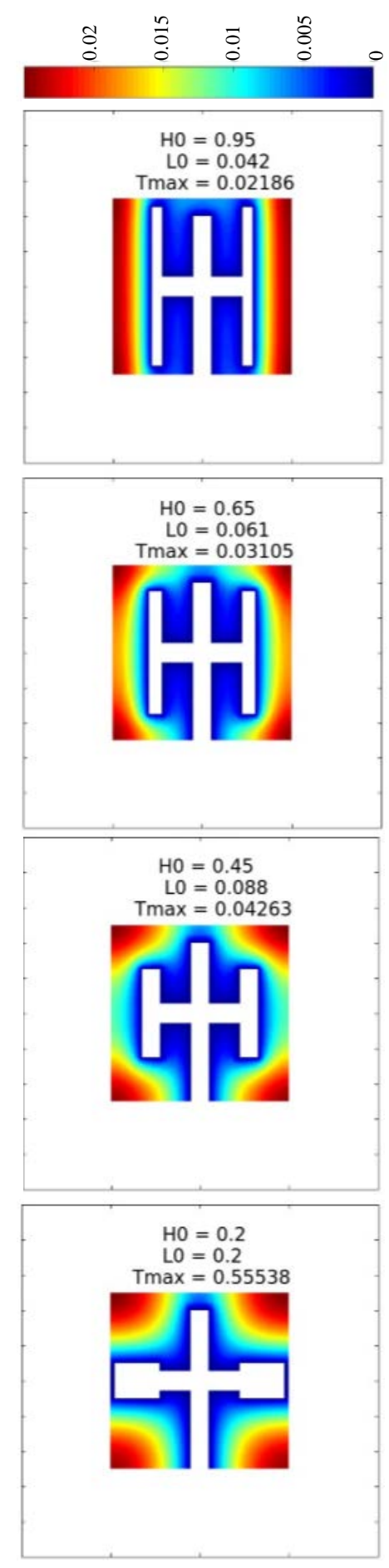

Figure 6. Temperature field in the solid domain as a function of the ratio $\mathrm{H}_{0} / \mathrm{L}_{0}$. 


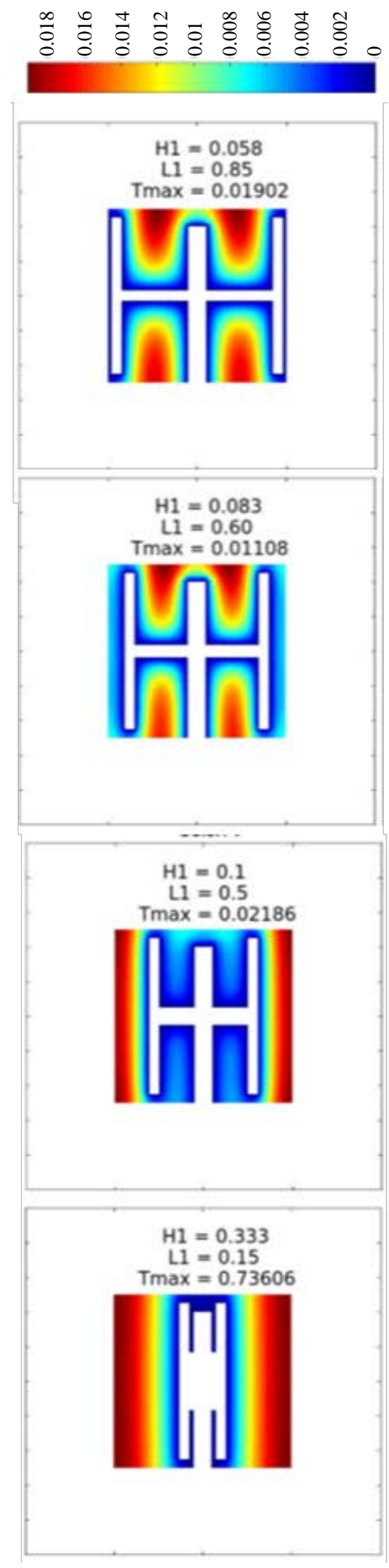

Figure 7. Temperature field in the solid domain as a function of the ratio $\mathrm{H}_{1} / \mathrm{L}_{1}$.

Figures 6 and 7 illustrate the search for the geometric configuration that minimizes the temperature field. It is possible to perceive individually the progress of each degrees of freedom defined in the solid domain.

However, obtaining the minimized temperature field should take into account the interaction and possible combinations between degrees of freedom. Hence, the process performed in the complete domain of application finds the optimal solution in every search space. Finally, the new geometry is proposed presenting the configuration that minimized the temperature field and the comparison with the initial proposed configuration, Fig. 7.

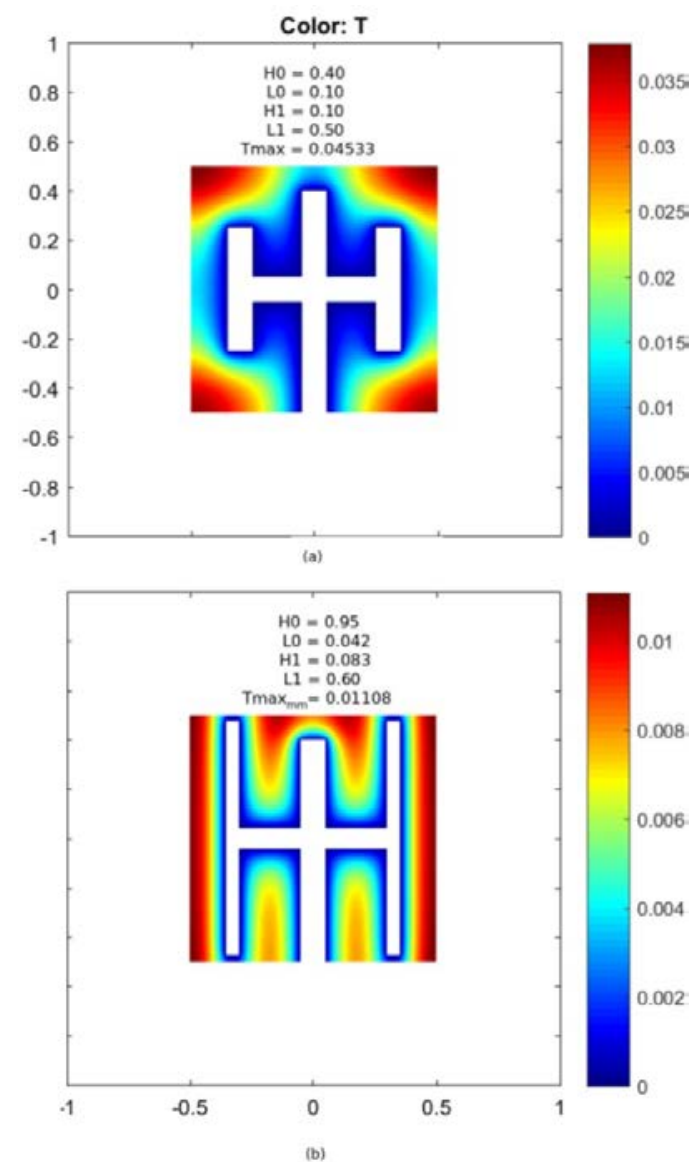

Figure 7. Comparison between the initial geometry and the final geometric configuration optimized.

It is possible to verify in Fig. 7(a) the geometry initially proposed for the problem. However, it is noted that after the process of searching for the minimum temperature field on the proposed geometric configuration, the domain changed and thereby a new cavity is obtained which provides a minimized temperature field. Figure 7(b) shows the final geometric configuration for the problem with the minimized solution. In the comparison, it is possible to verify the temperature field twice minimized, $\left(\mathrm{T}_{\max }\right)_{\mathrm{mm}}$, according to each degrees of freedom defined. The comparison between the temperature fields show that the original field has a poor distribution in comparison with the optimal one, which has 6 regions of higher magnitude. In other words, the cavity distribution must be performed in such way the highest temperature regions be uniformly distributed along the solid domain.

\section{CONCLUSIONS}

A study was carried out on heat transfer in 
solids with complex cavity, evaluating the geometry with Constructal Design method. The present problem was submitted to constant cavity area and two degrees of freedom $\left(\mathrm{H}_{0} / \mathrm{L}_{0}\right.$ and $\left.\mathrm{H}_{1} / \mathrm{L}_{1}\right)$. Other geometric variables were fixed. For each geometrical configuration, the heat diffusion equation was solved with the Finite Element Method (FEM).

Results showed that Constructal Design was effective in the improvement of thermal performance of the evaluated system. For example, for $\mathrm{H}_{1} / \mathrm{L}_{1}=0.6$ the best performance was five times better than that reached for the worst shape. Moreover, results showed that the distribution of temperature field is strongly affected by the geometry. The best performance is achieved when the vertical branches are thorough intruded in the solid domain and horizontal branch has an intermediate configuration, which leads to 6 regions of high temperature. In other words, the best shapes are obtained for the temperature fields with most homogeneous distribution of temperature field, according to constructal principle of optimal distribution of imperfections.

\section{ACKNOWLEDGMENTS}

Prof. E. D. dos Santos thanks CNPq by research grant and financial support (Project Process: 445095/2014-8).

\section{REFERENCES}

Bejan, A., 2000, Shape and Structure, from Engineering to Nature, Cambridge University Press, New York.

Bejan, A., 2016, The Physics of Life: the Evolution of Everything, St. Martins Press, New York.

Bejan, A., and Lorente, S., 2008, Design with Constructal Theory, 1st Edition, Wiley.

Bejan, A., Zane, P., 2012, Design in Nature: how the consTructal Law Governs Evolution in Biology, Physics, Technology, and Social Organization, 1st Edition, Doubleday, New York.

Biserni, C., Rocha, L. A. O., and Bejan, A., 2004, Inverted Fins: Geometric Optimization of the Intrusion into a Conducting Wall, International Journal of Heat and Mass Transfer, Vol. 47, pp. 2577-2586.

Biserni, C.; Rocha, L. A. O., Stanescu, G., and Lorenzini, E., 2007, Constructal H-shaped Cavities According to Bejan's Theory, International Journal of Heat and Mass Transfer, Vol. 50, pp. 2132-2138.

Dos Santos, E. D., Machado, B. N., Zanella, M. M., Gomes, M. das N., Souza, J. A., Isoldi, L. A., and Rocha, L. A. O., 2014, Numerical Study of the Effect of the Relative Depth on the Overtopping Wave Energy Converters According to Constructal Design, Defect and Diffusion Forum, Vol. 348, pp. 232-244.

Gonzales, G. V., Estrada, E. da S. D.,
Emmendorfer, L. R., Isoldi, L. A., Xie, G., Rocha, L. A. O., and Dos Santos, E. D., 2015, A Comparison of Simulated Annealing Schedules for Constructal Design of Complex Cavities Intruded into Conductive Walls with Internal Heat Generation, Energy, Vol. 93, pp. 372-382.

Helbig, D., da Silva, C. C. C., Real, M. de V., Dos Santos, E. D., Isoldi, L. A., and Rocha, L. A. O., 2016, Study about Buckling Phenomenon in Perforated Thin Steel Plates Employing Computational Modeling and Constructal Design Method, Latin American Journal of Solids and Structures, Vol. 13, pp. 1912-1936.

Lorenzini, G., Biserni, C., Estrada, E. D., Isoldi, L. A., Dos Santos, E. D., and Rocha, L. A. O., 2014, Constructal Design of Convective Y-Shaped Cavities by Means of Genetic Algorithm, Journal of Heat Transfer, Vol. 136, No. 7, 071702-071702-10.

Lorenzini, G., Biserni, C., Link, F. B., Isoldi, L. A., Dos Santos, E. D., and Rocha, L. A. O., 2013, Constructal Design of T-shaped Cavity for Several Convective Fluxes Imposed at the Cavity Surfaces, Journal of Engineering and Thermophysics, Vol. 22, No. 4, pp 309-321.

Lorenzini, G., Garcia, F. L., Dos Santos, E. D., Biserni, C., and Rocha, L. A. O., 2012, Constructal Design Applied to the Optimization of Complex Geometries: T-Y-Shaped Cavities with two Additional Lateral Intrusions Cooled by Convection, International Journal of Heat and Mass Transfer, Vol. 55, pp. 1505-1512.

Lorenzini, G., and Rocha, L. A. O., 2009, Geometric Optimization of T-Y-shaped Cavity According to Constructal Design, International Journal of Heat and Mass Transfer, Vol. 52, pp. 4683-4688.

MATLAB, User's Guide, Version 6.0.088, Release 12, The Mathworks Inc, 2000.

Rodrigues, M. K., Brum, R. da S., Vaz, J., Rocha, L. A. O., Dos Santos, E. D., and Isoldi, L. A., 2015, Numerical Investigation about the Improvement of the Thermal Potential of an EarthAir Heat Exchanger (EAHE) Employing the Constructal Design Method, Renewable Energy, Vol. 80, pp. 538-551.

Vieira, R. S., Petry, A. P., Rocha, L. A. O., Isoldi, L. A., and Dos Santos, E. D., 2017, Numerical Evaluation of a Solar Chimney Geometry for Different Ground Temperatures by Means of Constructal Design, Renewable Energy, Vol. 109, pp. 222-234.

Xie, Z., Chen, L., and Sun, F., 2010, Geometry Optimization of T-Shaped Cavities According to Constructal Theory, Mathematical and Computer Modelling, Vol. 52, pp. 1538-1546. 